\title{
Г.Г.Онищенко ${ }^{1}$, М.А.Патяшина ${ }^{2}$, И.Г.Карнаухов ${ }^{3}$, В.Б.Зиатдинов ${ }^{4}$
}

\section{СТРУКТУРА ВЗАИМОДЕЙСТВИЯ ТЕРРИТОРИАЛЬНО ЗАКРЕПЛЕННЫХ ОРГАНОВ И УЧРЕЖДЕНИЙ И МОБИЛЬНЫХ КОМПЛЕКСОВ ЭКСТРАТЕРРИТОРИАЛЬНОГО НАЗНАЧЕНИЯ ПРИ ПРЕДУПРЕЖДЕНИИ И ЛИКВИДАЦИИ ПОСЛЕДСТВИЙ ЧС САНИТАРНО- ЭПИДЕМИОЛОГИЧЕСКОГО ХАРАКТЕРА (НА ПРИМЕРЕ УНИВЕРСИАДЫ-2013)}

\author{
${ }^{1}$ Российская академия наук, Москва, Российская Федерация; ${ }^{2}$ Управление Роспотребнадзора \\ по Республике Татарстан, Казань, Российская Федераџия; ${ }^{3}$ ФКУЗ «Российский научно-исследовательский \\ противочумный институт «Микроб», Саратов, Российская Федерачия; ${ }^{4}$ ФБУЗ «Центр гигиены \\ и эпидемиологии в Республике Татарстан», Казань, Российская Федераиия
}

В статье дано научное обоснование привлечения дополнительных сил и средств для обеспечения санитарноэпидемиологического благополучия населения в условиях массовых мероприятий с международным участием. Определены задачи и основные направления работы специализированной противоэпидемической бригады Роспотребнадзора в период подготовки и проведения XXVII Всемирной летней универсиады в Казани. Рассмотрены аспекты межведомственного взаимодействия сетевых структур и мобильных формирований санитарно-эпидемиологического и лечебно-профилактического профилей во время Универсиады-2013.

Ключевые слова: СПЭБ, массовые мероприятия, межведомственное взаимодействие, ЧС санитарноэпидемиологического характера, санитарно-эпидемиологическое благополучие.

\section{G.G.Onishchenko ${ }^{1}$, M.A.Patyashina ${ }^{2}$, I.G.Karnaukhov ${ }^{3}$, V.B.Ziatdinov ${ }^{4}$}

\section{Structure of Interaction between the Territorial Agencies and Institutions} and Extraterritorial Mobile Complexes in the Course of Prevention and Response to Emergency Situations of Sanitary-Epidemiological Character (by the Example of Universiade, 2013)

\begin{abstract}
${ }^{1}$ Russian Academy of Sciences, Moscow, Russian Federation; ${ }^{2}$ Rospotrebnadzor Administration in the Republic of Tatarstan, Kazan, Russian Federation; ${ }^{3}$ Russian Research Anti-Plague Institute "Microbe", Saratov, Russian Federation; ${ }^{4}$ Center of Hygiene and Epidemiology in the Republic of Tatarstan, Kazan, Russian Federation
\end{abstract}

The paper provides scientific substantiation for the deployment of auxiliary forces and facilities for the provision of sanitaryepidemiological welfare of the population under mass events with international participation. Identified are the tasks and key areas of the specialized anti-epidemic teams (SAET) of the Rospotrebnadzor activities during the preparation and carrying out of the XXVII World Summer Universiade in Kazan. Reviewed are the aspects of inter-agency cooperation between the network structures and mobile units of sanitary-epidemiological and medical-preventive bias during Universiade, 2013.

Key words: SAET, mass events, inter-agency cooperation, emergency situation of sanitary-epidemiological character, sanitaryepidemiological welfare.

Проведение крупных политических, культурных и спортивных мероприятий, привлекающих большое число участников и зрителей, становится неотъемлемой составляющей современной общественной жизни.

Проводимая Правительством Российской Федерации последовательная внешняя политика существенно укрепила позиции страны, сделала ее привлекательной для инвестиций в различных сферах экономики и местом для проведения крупных культурно-спортивных мероприятий, международных форумов, в том числе с участием первых лиц [1].

В современных условиях Российская Федерация неизменно получает право и доверие международного сообщества при проведении крупных спортивных мероприятий, таких как XXVII Всемирная летняя универсиада в 2013 г. в Казани, XXII Олимпийские игры и XI Паралимпийские зимние игры в 2014 г. в Сочи, чемпионат мира по водным видам спорта в 2015 г., чемпионат мира по футболу в 2018 г. [2].

Обеспечение санитарно-эпидемиологического благополучия населения в период подготовки и проведения массовых мероприятий с международным участием и готовности к возникновению чрезвычайных ситуаций санитарно-эпидемиологического характера (ЧС) является одной из важнейших задач страны-организатора.

На 58-й сессии Всемирной ассамблеи здравоохранения в 2005 г. были приняты международные медико-санитарные правила (ММСП), разработанные с участием Российской Федерации (РФ). В соответствии с требованиями ММСП эпидемиологический надзор осуществляется с учетом меняющейся эпидемиологической конъюнктуры, появления новых неизвестных инфекционных болезней и возвращения известных нозологических форм [4].

Безопасность участников и гостей массового мероприятия будет зависеть от степени внедрения ММСП в принимающей стране и уровня ее готовности к предупреждению и контролю ЧС с точки зрения методологического, технологического, материально-технического обеспечения, состояния 
кадровых ресурсов, а также адаптированности стационарных сетевых структур и мобильных формирований лечебно-профилактического и санитарно-эпидемиологического профиля к требованиям ММСП, гармонизации с ними национальной правовой, нормативной и методической базы в области санитарной охраны территории [5].

Вопросами обеспечения санитарно-эпидемиологического благополучия населения и реагирования на ЧС занимаются структуры здравоохранения санитарно-эпидемиологического и лечебно-профилактического профиля, действующие по территориальному принципу (в пределах закрепленных административных территорий), и мобильные формирования, функционирующие вне связи с административными территориями, т.е. по экстратерриториальному принципу.

Анализ организации проведения международных спортивных игр показал положительный опыт привлечения специальных (мобильных) формирований с целью усиления лабораторной службы, способных осуществлять забор проб воздуха (станции контроля воздуха), жидких и твердых проб для индикации и диагностики патогенных биологических агентов (ПБА) с помощью ПЦР в режиме реального времени (Ванкувер, 2010 г., Лондон, 2012 г.). Необходимо отметить, что привлечение мобильных противоэпидемических формирований обосновано и целесообразно при проведении массовых международных мероприятий и в Российской Федерации [1].

XXVII Всемирная летняя универсиада в Казани стала крупнейшей за всю историю существования студенческих Игр. В ней приняло участие 11778 спортсменов из 160 стран мира, более 150 тыс. гостей и зрителей, около 20 тыс. волонтеров.

ЧС в период Универсиады-2013 могла возникнуть как в результате эпидемического проявления инфекционных болезней, актуальных для Республики Татарстан, в том числе природно-очаговых, так и в случае заноса на территорию республики опасных инфекционных болезней, требующих проведения мероприятий по санитарной охране территории, в том числе неизвестной этиологии.

С ЧС сталкиваются, в первую очередь, территориально закрепленные учреждения здравоохранения и санитарно-эпидемиологического надзора, возможности которых в плане верификации и реагирования на ЧС, как правило, ограничены. Это связано с тем, что в повседневной деятельности эти учреждения не встречаются с такими ситуациями. Роль учреждений лечебно-профилактического профиля в реагировании на ЧС заключается, прежде всего, в правильной оценке ситуации, своевременном выявлении больного с подозрением на инфекционную болезнь, способную вызвать ЧС, своевременном проведении первичных противоэпидемических мероприятий, оперативной передаче информации в соответствии с комплексным планом по санитарной охране территории.

Поэтому чрезвычайно важно своевременное подключение мобильных формирований, предназначенных для реагирования на ЧС, и специализированных учреждений федерального и регионального уровней, обладающих соответствующим потенциалом. Мобильными формированиями являются специализированные противоэпидемические бригады (СПЭБ) противочумных институтов Роспотребнадзора, относящиеся в соответствии с постановлением Правительства Российской Федерации от 30.12.2003 г. № 794 к функциональной подсистеме надзора за санитарно-эпидемиологической обстановкой единой государственной системы предупреждения и ликвидации чрезвычайных ситуаций.

Современные СПЭБ - мобильные формирования экстренного реагирования, автономного функционирования, использующие передовые диагностические и информационные технологии, современное оборудование, укомплектованные по модульному принципу, способные решать задачи по ликвидации и предупреждению чрезвычайных ситуаций в области санитарно-эпидемиологического благополучия населения (ЧС) [3]. СПЭБ непосредственно подчиняется Руководителю Роспотребнадзора.

СПЭБ укомплектованы мобильными комплексами лабораторий различного профиля на базе автошасси. Лаборатории мобильного комплекса соответствуют общим требованиям, установленным в международном стандарте ИСО/МЭК 17025

Впервые в целях обеспечения санитарно-эпидемиологического благополучия населения в ходе проведения массового мероприятия (ММ) с международным участием (Универсиады-2013) в соответствии с приказом Роспотребнадзора от 08.05.2013 г. № 285 была задействована СПЭБ РосНИПЧИ «Микроб».

Основанием привлечения СПЭБ в ходе подготовки и проведения ММ является возникновение (риск возникновения) ЧС, являющейся объектом деятельности СПЭБ. Тактика использования СПЭБ в ходе обеспечения проведения ММ варьирует в зависимости от эпидемиологической обстановки, наличия эпидемиологических рисков, стоящих перед СПЭБ задач и планируемых объемов исследований. СПЭБ может задействоваться как в полном (или усиленном) составе, так и в виде отдельных лабораторных модулей или групп специалистов.

При возникновении ЧС спектр направлений взаимодействия сетевых структур и мобильных формирований санитарно-эпидемиологического и лечебнопрофилактического профилей будет максимальным. Но поскольку в режиме повседневной деятельности при проведении ММ ЧС может и не возникнуть вообще, то возможна постановка перед мобильными формированиями задач в повседневном режиме, которые и будут в данном случае определять направления взаимодействия с органами и учреждениями Роспотребнадзора и здравоохранения.

Так, перед СПЭБ РосНИПЧИ «Микроб» в соответствии с приказом Роспотребнадзора от 08.05.2013 г. № 285 в период проведения 
Универсиады-2013 в повседневном режиме были поставлены следующие задачи:

- обеспечение готовности к проведению лабораторной диагностики, противоэпидемических (профилактических) мероприятий при выявлении больного (подозрительного) на особо опасные инфекционные болезни и при регистрации очагов инфекционных болезней с групповой заболеваемостью;

- оказание практической и методической помощи органам и организациям Роспотребнадзора, здравоохранения Казани по вопросам готовности к работе в условиях ЧС санитарно-эпидемиологического характера;

- усиление лабораторной базы учреждений Роспотребнадзора Казани, участие в мониторинге возбудителей инфекционных болезней в материале от людей и из объектов окружающей среды в соответствии с утвержденными документами «Порядок лабораторного обеспечения исследований окружающей среды в период проведения Универсиады-2013 в г. Казани» и «Порядок лабораторного обеспечения диагностики инфекционных болезней в период проведения Универсиады-2013».

Исходя из указанных задач, были определены алгоритмы взаимодействия СПЭБ с учреждениями и органами Роспотребнадзора и здравоохранения Республики Татарстан в рамках осуществления лабораторной диагностики материала от больных и из объектов окружающей среды. Из медицинских организаций Казани клинический материал должен был (по согласованию с Управлением Роспотребнадзора по Республике Татарстан) направляться на исследование в СПЭБ в случаях подозрения на особо опасные инфекции и вспышки инфекционных болезней; выявления заболеваний неясной этиологии; необходимости усиления при больших объемах лабораторных исследований; необходимости верификации диагноза.

Из ФБУЗ «Центр гигиены и эпидемиологии в Республике Татарстан» материал для исследования из объектов окружающей среды должен был (по согласованию с Управлением Роспотребнадзора по Республике Татарстан) направляться на исследование в СПЭБ в следующих случаях: подозрения на особо опасные инфекции; неизвестного ПБА; необходимости усиления при проведении бактериологических и санитарно-микробиологических исследований; необходимости верификации диагноза.

С учетом потенциальных эпидемиологических рисков необходимо было актуализировать схемы реагирования на ЧС с учетом включения мобильных формирований.

В Республике Татарстан в период подготовки и проведения Универсиады-2013, вопросы межведомственного взаимодействия при обеспечении санитарно-эпидемиологического благополучия и реагировании на ЧС регламентировались Комплексным планом мероприятий по санитарной охране территории Республики Татарстан от завоза и распространения инфекционных болезней, кото- рые могут привести к возникновению ЧС в области санитарно-эпидемиологического благополучия населения на 2011-2015 гг., утвержденным распоряжением КМ РТ от 03.09.2011 г. № 1665-р и изменениями от 10.01.2013 г.

В соответствии с упомянутым Комплексным планом в обеспечении санитарно-эпидемиологического благополучия в период подготовки и проведения Универсиады-2013 был задействован ряд ведомств (рис. 1). Кроме того, на период Универсиады в Комплексный план по санитарной охране территорий от заноса и распространения опасных инфекционных болезней был включен отдельный раздел, содержащий организационные и противоэпидемические мероприятия в период подготовки к Универсиаде, в том числе с участием СПЭБ ФКУЗ РосНИПЧИ «Микроб».

В соответствии с Постановлением Кабинета Министров РТ от 30.05.2013 г. № 363 «Об организации радиационной, химической и биологической защиты и контроля в период подготовки и проведения XXVII Всемирной летней универсиады 2013 года в г. Казани» в целях обеспечения радиационной, химической и биологической защиты и контроля в период подготовки и проведения Универсиады-2013 был утвержден состав группировки сил радиационной, химической и биологической защиты и контроля. В состав группировки республики впервые была включена СПЭБ ФКУЗ РосНИПЧИ «Микроб».

В целях обеспечения эффективного процесса управления Играми в период проведения Универсиады и своевременного реагирования при возникновении нештатных ситуаций был создан Центр управления Играми (ЦУИ), в рамках которого функционировал оперативный штаб по вопросам медицинского и санитарно-эпидемиологического обеспечения Универсиады.

Организационная структура оперативного штаба ЦУИ работала как система управления медицинским и санитарно-эпидемиологическим обеспечением Игр и представляла собой единую систему межведомственного взаимодействия, функционирующую в режиме повышенной готовности и осуществляющую постоянный взаимообмен информацией, главным образом, с оперативными штабами медицинского и санитарно-эпидемиологического направления.

Взаимодействие оперативного штаба Управления Роспотребнадзора по РТ со специалистами СПЭБ РосНИПЧИ «Микроб» было организовано непосредственно через координаторов оперативного штаба, а также через оперативный штаб ФБУЗ «ЦГиЭ в РТ», который осуществлял координацию работы ФКУЗ РосНИПЧИ «Микроб» в период проведения Универсиады-2013 (рис. 2). Работа оперативных штабов Управления Роспотребнадзора по РТ и ФБУЗ «ЦГиЭ в РТ» проводилась согласованно.

В ежедневном формате проводились рабочие совещания по вопросам организации работы, подготовки донесений, корректировки количества лабораторных исследований. Взаимообмен информацией 


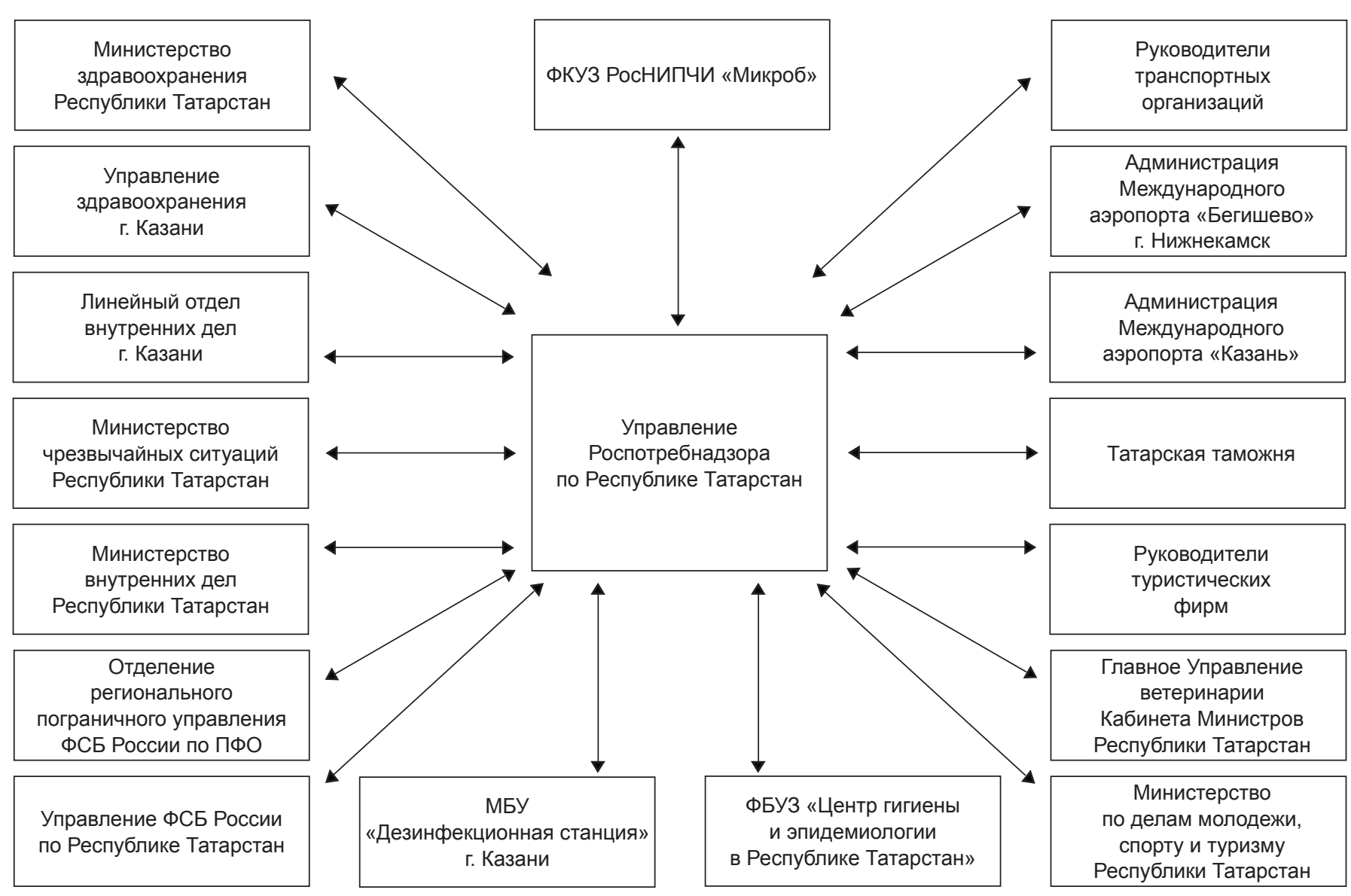

Рис. 1. Схема взаимодействия учреждений Роспотребнадзора по Республике Татарстан

проводился круглосуточно, информация о нестандартных пробах, регистрации экстренных извещений о случаях возникновения инфекционных заболеваний среди участников Универсиады-2013 и приданных сил, а также о случаях подозрения на ЧС химического и радиационного характера доводилась до сведения заинтересованных лиц немедленно, все противоэпидемические и санитарно-гигиенические мероприятия проводились своевременно, в полном объеме.

Таким образом, рассматривая вопросы взаимодействия территориально закрепленных органов и учреждений и мобильных комплексов экстратерриториального назначения при предупреждении и ликвидации последствий ЧС, можно сделать следующие выводы:

1. Внутриведомственное взаимодействие сетевых структур и мобильных формирований определяется какобщимизадачамилечебно-профилактической и санитарно-эпидемиологической службы, так и теми задачами, которые ставятся перед мобильными формированиями в конкретной ситуации.

2. Функции мобильных формирований, направляемых дополнительно для обеспечения санитарноэпидемиологического благополучия в период проведения ММ в режиме повседневной деятельности при отсутствии ЧС, определяются, прежде всего, соответствующими ведомственными приказами о направлении формирования. Специально для таких случаев должны разрабатываться документы, которые более подробно регламентируют функции конкретного мобильного формирования в режиме повседневной деятельности и, соответственно, вопросы внутриведомственного и межведомственного взаимодействия (порядки, регламенты и пр.).

3. При ежегодной корректировке Комплексных планов мероприятий по санитарной охране территории в период подготовки к проведению ММ необходимо предусмотреть наличие в Комплексном плане дополнительного раздела «Организационные и противоэпидемические мероприятия в период подготовки и проведения ММ» с обязательным включением мобильных формирований.

4. Вопросы межведомственного взаимодействия в период проведения ММ решаются в рамках работы межведомственного оперативного штаба медицинского и санитарно-эпидемиологического обеспечения массового мероприятия, а также оперативных штабов Управления Роспотребнадзора по субъекту Российской Федерации, ФБУЗ «Центр гигиены и эпидемиологии в субъекте Российской Федерации».

5. Разработан алгоритм и порядок взаимодействия территориально закрепленных органов и учреждений и мобильных комплексов экстратерриториального назначения при предупреждении и ликвидации последствий ЧС санитарно-эпидемиологического характера в условиях проведения массовых спортивных мероприятий.

В период подготовки и проведения Универсиады- 


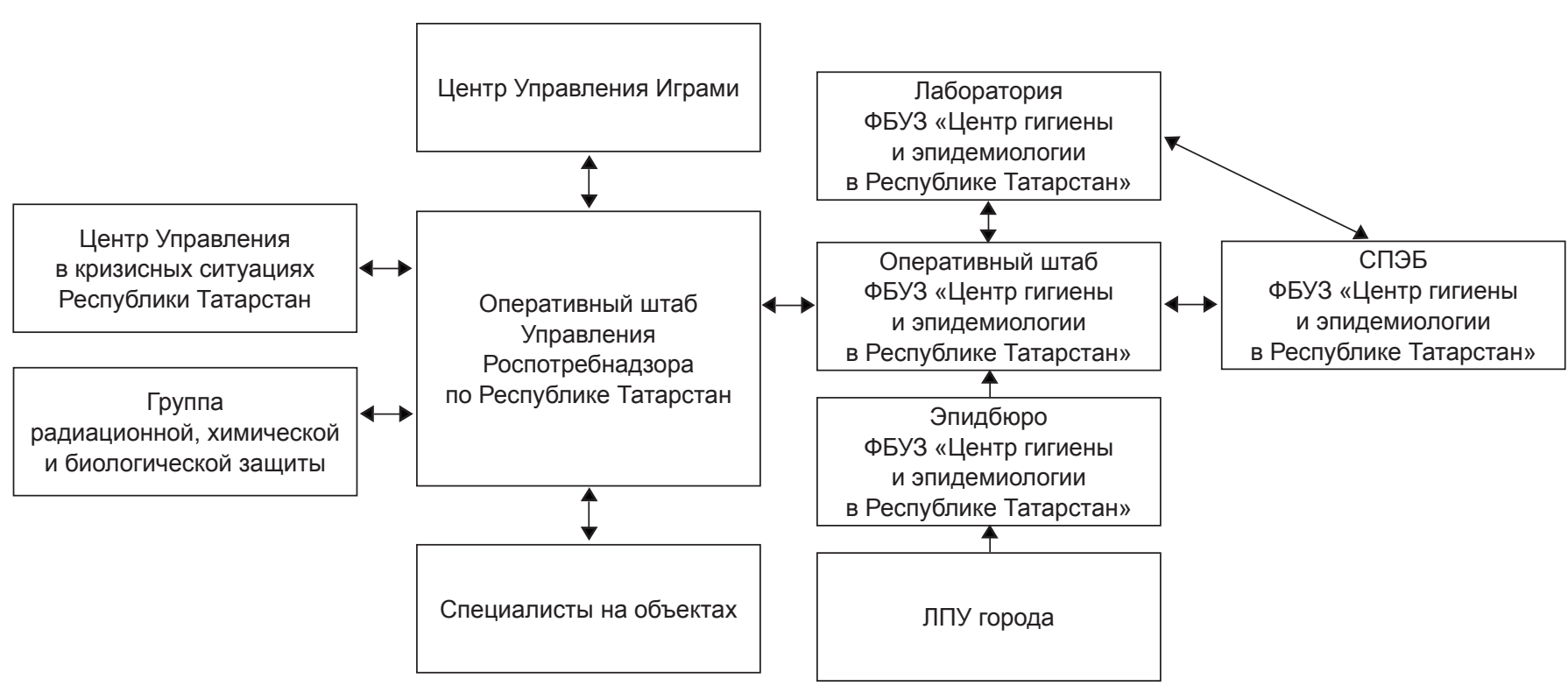

Рис. 2 Схема взаимодействия Оперативных штабов Управления Роспотребнадзора по Республике Татарстан и ФБУз «Центр гигиены и эпидемиологии в Республике Татарстан»

2013 была разработана и успешно апробирована структура взаимодействия территориально закрепленных органов и учреждений и мобильных комплексов экстратерриториального назначения при предупреждении и ликвидации последствий ЧС санитарно-эпидемиологического характера.

Авторы подтверждают отсутствие конфликта финансовых/нефинансовых интересов, связанных с написанием статьи.

\section{СПИСОК ЛИТЕРАТУРЫ:}

1. Онищенко Г.Г., Кузькин Б.П., Ракитин И.А., Башкетова Н.С., Коржаев Ю.Н., Гречанинова Т.А., Дятлов И.А., Кутырев В.В., Топорков А.В., Карнаухов И.Г., Топорков В.П., Щербакова C.А., Казакова Е.С., Шарова И.Н. Обеспечение санитарноэпидемиологического благополучия в период подготовки и проведения саммита «группы двадцати» в Санкт-Петербурге в 2013 г. Сообщение 2. Организация и приоритетные направления работы в период проведения саммита. Пробл. особо опасныхх инф 2013; 4:11-15.

2. Онищенко Г.Г., Кутырев В.В., редакторы. XXVII Всемирная летняя Универсиада 2013 года в Казани. Обеспечение санитарно-эпидемиологического благополучия. Тверь: Триада; 2013. 528 с.

3. Онищенко Г.Г., Кутырев В.В., Топорков А.В., Карнаухов И.Г., Щербаков Д.А., Казакова Е.С., Щербакова С.А. Обеспечение модернизации специализированных противоэпидемических бригад (СПЭБ) на современном этапе. Пробл. особо опасных инф. 2009; 3(101):10-8.

4. Топорков А.В., Топорков В.П., Шиянова А.Е., Кутырев B.В. Чрезвычайная ситуация в области санитарно-эпидемиологического благополучия населения как унифицированный объект надзора и оперативного реагирования в рамках современной стратегии борьбы с инфекционными болезнями. Пробл. особо опасных инф. 2009; 2(100):5-10.

5. Удовиченко С.К., Топорков А.В., Карнаухов И.Г., Сафронов В.А., Кедрова О.В., Топорков В.П., Кутырев В.В. Оценка внешних и внутренних угроз санитарно-эпидемиологическому благополучию населения в условиях проведения массовых спортивных мероприятий. Пробл. особо опасных инф. 2013; 2:26-32.

\section{References}

1. Onishchenko G.G., Kuz'kin B.P., Rakitin I.A., Bashketova N.S.,
Korzhaev Yu.N., Grechaninova T.A., Dyatlov I.A., Kutyrev V.V., Toporkov A.V., Karnaukhov I.G., Toporkov V.P., Shcherbakova S.A., Kazakova E.S., Sharova I.N. [Sanitary-epidemiological welfare provision in the preparations to and management of the "G-20" Summit in Saint-Petersburg, 2013. tions to and management of the "G-20" Summit in Saint-Petersburg, 2013.

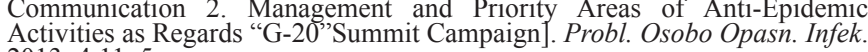
2013; 4:11-5.

2. Onishchenko G.G., Kutyrev V.V., editors. [XXVII World Summer Universiade 2013 in Kazan. Provision of Sanitary and Epidemilogical WellBeing]. Tver: Triada; 2013. 528 p.

3. Onischenko G.G., Kutyrev V.V., Toporkov A.V., Karnaukhov I.G. Scherbakov D.A., Kazakova E.S., Scherbakova S.A. [Provision of Specialized Anti-Epidemic Teams (SAET) Modernization at the Present Stage]. Probl. Osobo Opasn. Infek. 2009; 3(101):10-8.

4. Toporkov A.V., Toporkov V.P., Shiyanova A.E., Kutyrev V.V. [Emergency Situation in the Sphere of Population Sanitary and Epidemiologic Welfare as Unified Object of Surveillance and Active Response in the Scope of Up-To-Date Strategy of Infectious Diseases Control]. Probl. Osobo Opasn. Infek. 2009; 2(100):5-10.

5. Udovichenko S.K., Toporkov A.V., Karnaukhov I.G., Safronov V.A., Kedrova O.V., Toporkov V.P., Kutyrev V.V. [Evaluation of External and Internal Threats to Sanitary-Epidemiological Welfare of the Population in the Context of Mass Sporting Events]. Probl. Osobo Opasn. Infek. 2013; $2: 26-32$.

Authors: Federation.

Onishchenko G.G. Russian Academy of Sciences. Moscow, Russian

Patyashina M.A. Rospotrebnadzor Administration in the Republic of Tatarstan. 30, B. Krasnaya St., Kazan, 420111, Russian Federation. E-mail: org@16.rospotrebnadzor.ru

Karnaukhov I.G. Russian Research Anti-Plague Institute "Microbe" 46, Universitetskaya St., Saratov, 410005, Russian Federation. E-mail: rusrapi@microbe.ru

Ziatdinov V.B. Center of Hygiene and Epidemiology in the Republic of Tatarstan. 13a, Sechenova St., Kazan, 420061, Russian Federation. E-mail: fguz@16.rospotrebnadzor.ru

Об авторах: Москва.

Онищенко Г.Г. Российская академия наук. Российская Федерация,

Патяшина М.А. Управление Роспотребнадзора по Республике Татарстан. Российская Федерация, 420111, Казань, ул. Б. Красная, 30. E-mail: org@16.rospotrebnadzor.ru

Карнаухов И.Г. Российский научно-исследовательский противочумный институт «Микроб». Российская Федерация, 410005, Саратов, ул. Университетская, 46. E-mail: rusrapi@microbe.ru

Зиатдинов В.Б. Центр гигиены и эпидемиологии в Республике Татарстан. Российская Федерация, 420061, Казань, ул. Сеченова 13 а. E-mail: fguz@16.rospotrebnadzor.ru

Поступила 04.02 .15 . 